\title{
Role of Learning Management System in Distance Education: A Case Study of Virtual University of Pakistan
}

* Waqas Ahmed, PhD Scholar (Corresponding Author)

** Dr. Qaisara Parveen, Assistant Professor

*** Dr. Muhammad Arshad Dahar, Assistant Professor

\begin{abstract}
This case study is an overview of prevailing eight-dimensioned frameworks of e-learning for LMS in the Virtual University of Pakistan. This study outlines two dimensions i.e. pedagogy and evaluation out of prevailing eight-dimensions. The main objective of the study was to overview the role of pedagogical and evaluation aspects in distance programs offered through the learning management system. A total of 150 male and female students enrolled in spring and fall semesters in the year 2019 of two-year master level programs of twin cities Rawalpindi and Islamabad were selected through a stratified sampling technique for the study. The researcher developed a questionnaire and verified its validity and reliability for collecting data. Statistical analyses such as mean and standard deviations were used to analyze the questionnaire. The findings of the research are that prevailing LMS is functioning effectively and appropriately as respondents determine in their constructive and optimistic responses regarding the role of learning management system offered by the university in distance learning programs. It is concluded that the functioning of LMS is appropriate and effective. It is recommended that LMS would be useful and effective in any pandemic and prevailing type of situation. The same pattern of LMS is useful during Covid for formal universities.
\end{abstract}

Keywords: Learning Management System, E-learning, Distance Education, Pedagogy, Evaluation Introduction

Increasing demands of life-long learning and progress in technologies, online learning is a widely used way of learning (Ahmed, Hussain \& Farid, 2018). There is a worldwide shift in distance learning due to considerable development in electronic media and online learning options. Most of the universities in the world are operating with different Learning Management Systems (LMS) aiming at their academic activities in distance education programs. Consequently, Virtual learning is becoming a powerful and leading genre of distance education globally including in Pakistan (Ali, Ahmed, Shaikh, and Bukhari, 2011). The need for a sound learning management system to cope with emerging models of distance learning programs is becoming more obvious in developing countries such as Pakistan. Though, prevailing e-learning programs need support to cope with challenges and issues coming forth (Sangi \& Ahmed, 2015).

With the improvement in online and distance learning, many renowned universities across the world have started online initiatives like offering online-courses, professional certificates, and onlinecollege degree programs with the help of learning management systems (Ohliati \& Abbas, 2019). In Pakistan, some formal education universities have been applying different learning management systems (LMS) and contributing their efforts but LMS is functional to some extent, and on the other hand, distance education universities are looking forward to having sound learning management systems that will offer the best education delivery services to adult learners in the online environment. Still, some other types of learning management systems and related initiatives are on the way in nonformal universities in Pakistan but still, several issues and challenges have to be deal with. (Sangi \& Ahmed, 2015).

\footnotetext{
* Department of Education, PMAS-Arid Agriculture University, Rawalpindi

Email: waqas.education@gmail.com

** Department of Education, PMAS-Arid Agriculture University, Rawalpindi Email: qaisarach@yahoo.com

*** Department of Education, PMAS-Arid Agriculture University, Rawalpindi

Email: dr.arshad1969@uaar.edu.pk
} 
In Pakistan, the number of enrolled students, the number of institutions, and teachers is improving day by day (Pakistan Economic Survey, 2016). Hence, distance education, is currently, educating lots of people and preparing them for future career opportunities without restrictions to be physically present in a classroom or on a structured topographical venue. (Chen et al. 2018).

During the past decades, distance education has experienced a revolutionary shift i.e., moving from physical classroom learning to virtual \& distant learning (Sadikin et al., 2019). Therefore, a new trend is appreciated by learners, who perceived it more convenient to acquire their distant or virtual education from their easiest location points with minimal cost. (Gómez \& Rodríguez Marciel, 2012; Moyle, 2010). Now, it is proved statistically that a large number of learners are managing education costs through distance learning programs. (Moyle, 2010) Learning management systems (LMS) and online learning are interconnected. Consequently, every distant university is crafting its learning management system (LMS) and making it accessible with convenience for distant learners to get their education from remote \& manageable areas (Alhosban, \&Ismaile, 2018).

The present study tries to present an overview of the prevailing learning management system (LMS) offered through distance learning programs as for as their pedagogical and evaluation dimensions of LMS are concerned. Distance universities in Pakistan are certainly contributing to distant higher education both financially as well as economically. Its impact is visible on distant learners' decision-making and suitability to acquire education through distance learning programs. On the other hand, The eight-dimensioned Learning management system (LMS) has twisted an exemplar swing and proved itself a transformation agent for old-style distance pedagogy and adult learning at higher distance education universities (Ahmed, Hussain \& Farid, 2018).

Literature Review: Distance education is the generic all-inclusive term used to state a mode of learning which focuses on delivering education to students who are not physically present "on the site" to get an education. In the past correspondence was involved in distance education. Now it turned into online. In other words, it is a getting education with physical separation of teacher and learner. Distance education is a mode of learning in which physical separation sandwiched between student and teacher is evident. (Sangi \& Ahmed, 2015) it is also known as distance learning; distributed learning etc. (Moore, Camille, \& Krista, 2011)

Distant education \& E-learning is gaining popularity increasingly all over the world and in Pakistan as well. At present, distance learning is well-thought-out a cheaper \& convenient mode of learning which facilitates adults and working professionals learning. So, several enrolled students in distance and E-learning has been growing very fast in many countries but rapidly in emerging economies. Learning opportunities for people of different areas, ages, and learning abilities were increased in distance learning. (Sangi \& Ahmed, 2015)

Due to development in Web-based technologies different instructional software were developed Learning Management Systems (LMSs) is an example of a widely used powerful software system it is being used extensively in the US, UK, Canada Australia, and Pakistan. Learning Management Systems (LMS) is one of the leading software systems used in supporting distance learning in higher education academic institutions to improve the teaching and learning experiences of students. Learning Management Systems (LMS) are operative in the majority of higher education institutions in Pakistan. As LMS offers numerous benefits to individuals and universities. Therefore, many universities have deployed some or other form of LMS. Students can access course materials at any time and from any location. Due to this, it opens up new possibilities for the initiation of new technological innovations in the fields of education where students easily deal with learning and become active participants. Managing online courses are easy for instructors. LMS allows instructors to add courses, providing feedback and tracking the whole teaching-learning process. These LMS are having various web-based features envisioned to support learning activities. LMS enables faculty members to share learning materials as well as providing interaction with their students both synchronously and asynchronously. (Turnbull, Chugh \& Luck, 2019). The widely adopted LMS are Blackboard, Sakai, KEWL, and Moodle etc. (Unwin et al. 2010).

Gradually, other universities began shifting towards the use of e-learning techniques such as Learning Management Systems (LMS) and video conferencing as an alternative to conventional university education. The challenges of E-learning are greater as compare to its benefits. (Siddiquei, 2017). Although these initiatives have been encouraging, Pakistan still has to go a long way to reap the benefits of e-learning to compete with international educational standards. E-learning programs 
offered by institutes need a depth review to highlight the issues which cause failure to get the advantages. (Qureshi et al. 2012)

Khan's (2001) eight dimensioned-framework also referred to as 'factors' was developed as an exemplar of effective Web-based instruction as defined in Web-Based Instruction (1997). This framework does take into consideration the design, development, delivery, and evaluation of webbased and hybrid instruction and can provide guidance. This LMS, sometimes also called a learning platform comprised of subsystems or dimensions to help both instructors and students alike. (Benta, \& Dzitac, 2014) Recognizing the importance of dimension or platform, universities are modifying their evaluation strategies also by adopting different technologies. Different universities used practical and detailed checklists for self-assessment to evaluate their educational setup for its growth. (Muhammad, Al-Karaki, 2008). Certainly, e-learning systems have open new frontiers of pedagogy. (Benta, \& Dzitac, 2014). The pedagogical dimension addresses instructional issues relating to content and design analysis, selection of teaching-learning methodologies and strategies etc. whereas the evaluation dimension deals with assessment of learners; evaluation of the instruction and learning environment. (Khan, 2001)

Colace, De Santo, \& Vento (2003) says that there are different LMS in practice with characteristics and services. They viewed that to see the functioning of e-learning LMS platforms, a series of functions should be analyzed carefully to sketch usability \& functioning of the current learning management systems in the context of both evaluation and pedagogy. It is also important to understand how they are integrated to facilitate learning and evaluation.

Virtual university can be viewed as an education-providing unit where a timeless, spaceless, border-less environment is provided to its students with reality amplified and easily acquired education with the help of the internet. Online students should not require to come physically on campus. (Khan, \& Bhatti, 2012) Virtual University of Pakistan uses online instructions where correspondence is made through emails Virtual University of Pakistan does not conduct tutorials for its students. There is a comprehensive Learning Management System (LMS). Online teaching takes play through LMS. Separate login and password are allotted to each student to open LMS. It has a lecture schedule for the whole semester. Students can view their recorded lectures on LMS. Discussion Boards have a very important role in a Learning Management System. Owing to the progression of the latest instructional technologies, multiple blended and e-learning modules were adopted by education institutions and universities. Learning Management System (LMS) being a powerful e-learning software in distance learning institutions. So it is necessary to learn the benefits and challenges of pedagogical and evaluation aspects of LMS faced by the learners to improve the distance education programs.

Objectives of the Study

The objective of this study were:

1. To outline the role of pedagogical aspects in distance programs offered through the learning management system

2. To overview the role of evaluation aspects in distance programs offered through the learning management system

\section{Research Questions}

R1: How do male and female students perceive pedagogical aspects in distance programs offered through the learning management system?

R2: How do male and female students perceive evaluation aspects in distance programs offered through the learning management system?

Research Methods: This was a case study that utilized a quantitative paradigm. The purpose of the study was to understand how students overview eight-dimensioned learning management systems in light of pedagogical and evaluation aspects. The participants comprised of two years master level students of Virtual University of Pakistan, studying in the spring and fall semester of year 2019 at Public Campuses of Rawalpindi and Islamabad Cities. A self-developed questionnaire was used to collect the data. The questionnaire was framed based on the five-point Likert scale $1=$ strongly disagree, $2=$ disagree, $3=$ neutral, $4=$ agree, and $5=$ strongly agree. The data was collected through personal visits and an on-line Google survey form. The quantitative data received from respondents were analyzed through Mean and standard deviation. 
Data Collection and Analysis: the study shows the following results and perceptions:

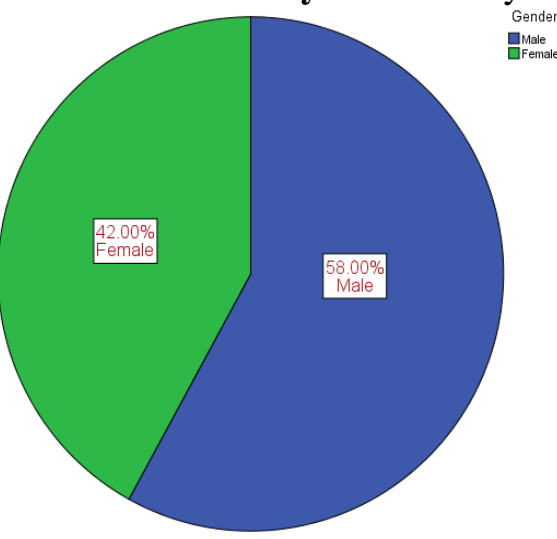

Figure 1: Gender Wise Sample Percentage

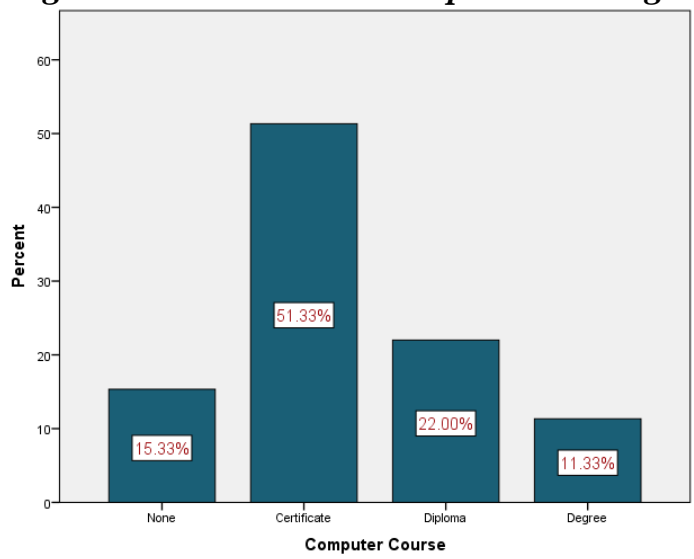

Figure 3: Computer Course

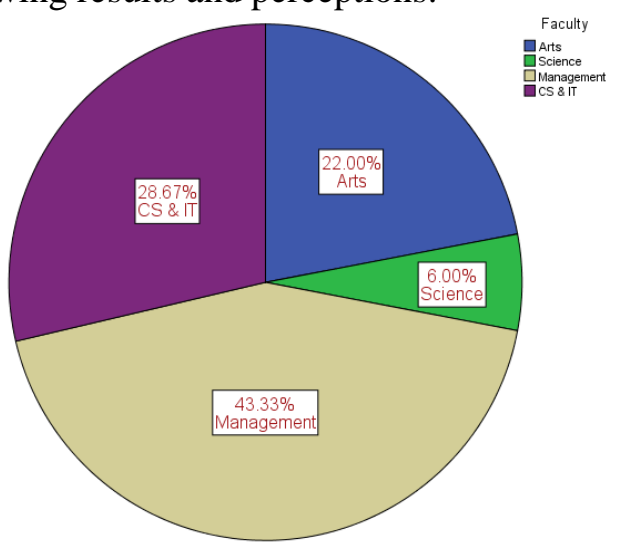

Figure 2: Faculty Wise Sample Percentage

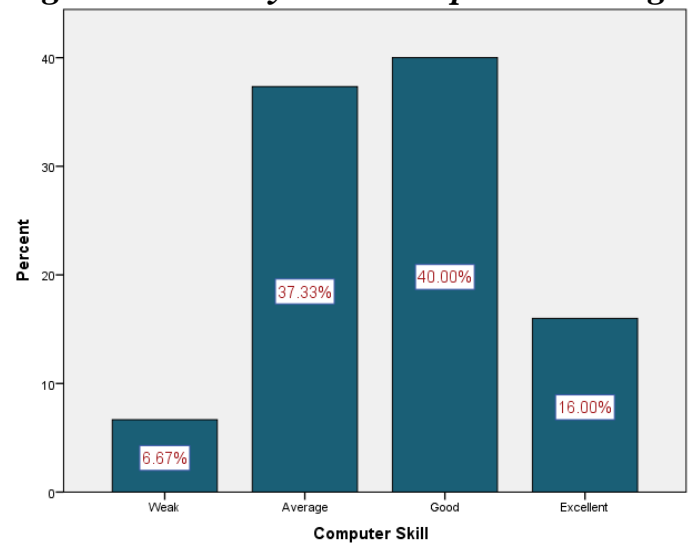

Figure 4: Computer Skill

Figures 1 and 2 shows that $58 \%$ of respondents were male and $42 \%$ female while faculty-wise majority of the respondents belonged to Management (43.33\%) and Computer Science \& Information Technology (28.67\%). Others belonged to Arts (22.00\%) and Science (6.00\%). According to figure 3, $51.33 \%$ of respondents had Certificate Course, $22.00 \%$ Diploma, $11.33 \%$ a Degree holder and $15.33 \%$ have no computer course. The majority of the respondents had Good (40\%), Average (37.33\%), and Excellent (16.00\%) computer skills while some respondents had Weak $(6.67 \%)$ computer skills. (Figure 4).

Table 1: Pedagogical Aspects in LMS

\begin{tabular}{cllccc}
\hline \multirow{2}{*}{ Sr. No. } & \multirow{2}{*}{ Statement } & \multicolumn{2}{c}{ Male } & \multicolumn{2}{c}{ Female } \\
\cline { 3 - 5 } & & Mean & SD & Mean & SD \\
\hline 1 & Online lectures are clear and easy to understand. & 3.94 & 0.981 & 3.86 & 1.521 \\
2 & Learning materials are relevant and useful. & 4.28 & 1.008 & 4.60 & 1.415 \\
3 & It is easy to study material on a computer screen. & 3.16 & 1.704 & 2.46 & 1.641 \\
4 & Face-to-face contact with the instructor is necessary to & 4.00 & 1.381 & 4.35 & 1.409 \\
5 & The instructor's role in Discussion Board is adequate. & 3.44 & 1.428 & 3.89 & 1.139 \\
6 & It is difficult to communicate effectively on LMS. & 2.10 & 1.423 & 3.13 & 1.672
\end{tabular}

Table 1 shows that the mean value 3.0 or above is considered favorable to all six-item statements relating to pedagogical dimensions as ' 5 ' was the highest value at the Likert point scale for this research. Therefore, the result reflects the mean value of 3.94 and 3.86 respectively showing that the online lecture was clear and understandable to both male and female respondents. Moreover, SD values are ranging $0.981 \& 1.521$ values for male and female respondents. Likewise the mean values $4.28 \& 4.60$ respectively for male \& female about relevance and usefulness of learning materials parameter representing high relevance and usefulness of material to both groups of respondents. The Standard deviation range of respondent groups is $1.008 \& 1.415$. On the other hand, the mean value "on the easiness of study material on a computer screen" was 3.16 for male respondents as compared 
with 2.46 for female respondents which shows that it was not easy for females to study material on a computer screen. However, both respondents gave opinion that face-to-face contact with the instructor is highly necessary to learn with mean values $4.00 \& 4.35$ for male and female respondents respectively. On the adequacy of instructor's role in "Discussion Board" means values are 3.44 for male respondents \& 3.89 for female respondents respectively which reflects that both respondents think in the same way. Nevertheless, the mean values for the statement "It is difficult to communicate effectively on LMS" are 2.10 for male respondents \& 3.13 for female showing that males think it is not difficult to communicate on LMS as compared to female respondents.

Table 2: Evaluation dimensions in LMS

\begin{tabular}{|c|c|c|c|c|c|}
\hline \multirow{2}{*}{ Sr. No. } & \multirow{2}{*}{ Statement } & \multicolumn{2}{|c|}{ Male } & \multicolumn{2}{|c|}{ Female } \\
\hline & & Mean & SD & Mean & SD \\
\hline 1 & $\begin{array}{l}\text { The online quizzes helped me to focus my learning on } \\
\text { important topics of the courses. }\end{array}$ & 3.44 & 1.507 & 3.57 & 1.521 \\
\hline 2 & Electricity issues make failure in online quizzes. & 4.45 & 0.711 & 3.89 & 1.415 \\
\hline 3 & $\begin{array}{l}\text { Discussion Board is focused on the topic and organized } \\
\text { new ideas/thoughts. }\end{array}$ & 2.82 & 1.589 & 3.38 & 1.641 \\
\hline 4 & $\begin{array}{l}\text { Online examination is better than paper and pencil } \\
\text { form. }\end{array}$ & 3.68 & 1.475 & 3.83 & 1.409 \\
\hline 5 & The time duration of the examination is sufficient. & 3.68 & 1.544 & 3.10 & 1.672 \\
\hline 6 & Typing speed affects the results of online examinations. & 3.69 & 1.375 & 3.27 & 1.139 \\
\hline
\end{tabular}

Table 2 illustrates that in the case of evaluation dimension mean value 3.0 or above is considered positive to all six statements as ' 5 ' was the highest value at the Likert point scale in this study. The result echoes that both male \& female respondents with mean values are 3.44 and 3.57respectively have discoursed that online quizzes helped them to focus on studies. However, there is a difference of opinion on "Electricity issues" with mean values of 4.45 for male respondents and 3.89 for female respondents. Nevertheless, the mean values for the statement "Discussion Board is focused on the topic and organized new ideas/thoughts" are 2.82 for male respondents $\& 3.38$ for female showing that male respondents consider Discussion Boards are not organized on topic or ideas whereas female respondents see it focused on ideas and topics. On the other hand, the mean values $3.68 \& 3.83$ respectively for male \& female shows that there is relevance of opinion of both group respondents on parameter of online examination. Similarly, the mean value of "on-time duration of examination" was 3.68 for male respondents as compared with 3.83 for female respondents which shows that the time duration of examination is sufficient for both respondents. However, both respondents opinioned that typing speed affects the results of online examination with mean values $3.69 \& 3.27$ for male and female respondents respectively.

Sancar and Cagiltay (2008) try to answer that if the media used can restrict/enhance the teaching approaches or if we can adopt a variety of approaches regardless of media we use. On the other hand, it does not imply that delivery of instruction through media is not important, it supports the teaching-learning process but to make the same effects alternative media can also be used. Due to this, media selection should be done. Media selection should be done by considering the number of learners and their readiness, faculty instruction time factors

\section{Discussion and Conclusions}

It is found that the LMS of the Virtual University of Pakistan has great potential if challenges are addressed timely and effectively. LMS of the virtual university is doing well as pedagogy and learning environment is concerned; however, it is also evident from researches that without appropriate resources, tools, equipment and technology, and available resources, it will be challenging for students to perform \& learn well. Understanding online lectures are clear and easy. Learning material used by the university was also found relevant and useful. The majority of the respondents had computer courses and computer skills. Male feels that studying material on screen is easy. They prefer studying material on screen and feel it effectively while female is reluctant about that. These findings are consistent with those from the study conducted by MacKay (2011). According to males and females, face-to-face interaction is necessary to learn. The role of the instructor in the Discussion Board is sufficient. There is a significant difference between male and female communication through LMS. According to male it is difficult to communicate on LMS while female feels that 
communication through LMS is easy. Students' perception that online quizzes help out them to focus their learning on important topics of the courses. Electricity appears as a major issue in online quizzes. There is a conflict among males and females regarding the discussion board that is organized with new ideas or knowledge. Females had better experience than of discussion board and they agree that discussion board are focused and creates new ideas. According to males and females that online examinations are better than paper and pencil. They prefer online examinations as compared to paper examinations. The time duration of online examinations is sufficient. Typing speed also found a major drawback of online examination. Both males and females agreed that typing speed affects the results of online examinations.

In the light of the above conclusion, it is recommended that LMS would be useful and effective in any pandemic and prevailing situation. From the review of the literature, analysis of the distance learning program of the Virtual University of Pakistan and the survey conducted in the study, the learning management system of the university can help the other distance education universities too to serve as the basis for defining and upholding excellence for implementing their own LMS. This study may also prove helpful for the teaching faculty, course coordinators, and administrators to overview in-depth introduction of learning management systems in distance learning universities, ways of teaching and assessment, their strengths and weaknesses of the distance education programs.

\section{References}

Ahmed, M., Hussain, S., and Farid, S., (2018). Factors Influencing the Adoption of e-Learning in an Open and Distance Learning Institution of Pakistan. The Electronic Journal of e-Learning, 16(2), pp.148-158, available online at www.ejel.org. ISSN 1479-4403

Alhosban, F., \& Ismaile, S. (2018). Perceived Promoters of and Barriers to Use of a Learning Management System in an Undergraduate Nursing Program. International Journal of Emerging Technologies in Learning, 13(2), 226-233.

Ali, M., Ahmed, A., Shaikh, A.W. and Bukhari, A.H.S. (2011). "Impacts of Information Technology on E-learning System in Pakistan", Sindh University Research Journal (SURJ), 43(1), pp. 2934.

Chen, C.-C., Huang, C., Gribbins, M., \& Swan, K. (2018). Gamify Online Courses with Tools Built into Your Learning Management System (LMS) to Enhance Self-Determined and Active Learning. Online Learning, 22(3), 41-54.

Colace, F. De Santo, M., Vento, M. (2003) Evaluating Online Learning Platforms: a Case Study. Proceedings of the 36th Hawaii International Conference on System Sciences - 2003

Gómez, E., \& Rodríguez-Marciel, C. (2012). PGDnet: a new problem-solving virtual learning environment. British Journal of Educational Technology, 43, 576-591. doi: 10.1111/j.14678535.2011.01224.x

Khan, B. H. (2001). A framework for Web-based learning. In B. H. Khan (Ed.), Web-based training. Englewood Cliffs, NJ: Educational Technology Publications.

Khan, S. A. \& Bhatti, R. (2012). Application of social media in marketing of library and information services: A case study from Pakistan. Webology 9(1), 1-8.

Moyle, K. (2010). Building innovation: Learning with technologies. Australian Education Review, 56.

Moore, J., Camille, D., and Krista, G., (2011) "e-Learning, Online Learning, and Distance Learning Environments: Are They the same", Journal of Internet and Higher Education, Volume 11, pp. 129-135,

Muhammad, J. and Al-Karaki, J. (2008). Integrating Internet into Traditional Education: A Practical Study of University Students' Usage and Attitudes. The International Arab Journal of Information Technology, 5(3), 241-252.

Ohliati, J., \& Abbas, B. S. (2019). Measuring Students Satisfaction in Using Learning Management System. International Journal of Emerging Technologies in Learning, 14(4), 180-189. https://doi-org.ezproxy.umuc.edu/10.3991/ijet.v14 i0 4.9427

Pakistan Economic Survey. (2016). Available: http://finance.gov.pk/survey_1314.html [Accessed on 10th August, 2020]

Qureshi. I. A., Ilyas K., I Yasmeen R \& Whitty M., (2012) Challenges of implementing e-learning in a Pakistani university Knowledge Management \& E-Learning: An International Journal, Vol.4, No.3. 
Sadikin, M., Yusuf, R., \& Rifai, A. D. (2019). Load balancing clustering on Moodle LMS to overcome the performance issue of the e-learning system. Telkomnika, 17(1), 131-138.

Sancar, H.,\& Cagiltay, K. (2008) Effective Use of LMS: Pedagogy through the Technology. In: EdMedia: World Conference on Educational Media and Technology, Vienna, Austria URL: https://www.editlib.org/p/28931/

Sangi, N., A \& Ahmed, M., (2015). OLIVE Framework for E-Learning Development at AIOU, Pakistan. Journal of Computer Science of Newports Institute of Communications and Economics Volume 6, Issue-2015, ISBN: 2226-3683

Siddiquei, N., \& Khalid, R., (2017). Emerging Trends of E-Learning in Pakistan: Past, Present and Future. International Journal of Law, Humanities \& Social Science Volume 2, Issue 1 (November 2017), P.P. 20-35

Turnbull, D., Chugh, R., \& Luck. J (2019) A. Tatnall (ed.), Encyclopedia of Education and Information Technologies, https://doi.org/10.1007/978-3-319-60013-0_248-1

Unwin, T. et al., (2010). Digital learning management systems in Africa: myths and realities. Open Learning: The Journal of Open and Distance Learning, 25(1), pp.5-23. 